\title{
INFLUENCE OF CHEWING LOAD ON WEAR RATE OF POLYMETHYL METHACRYLATE DOUBLE CROSS-LINKED DENTURE TEETH IN VITRO \\ Jean-François Roulet ${ }^{1 a^{*} \text { iD }}$, Abdullah AI-Naser ${ }^{2 b}$, William Martinc, Nader Abdulhameed ${ }^{\text {1d }}$, Chiayi Shen ${ }^{1 e}$
}

\author{
'Department of Restorative Dental Sciences, College of Dentistry, University of Florida, Gainesville, FL, USA \\ 2Department of Restorative Dental Sciences, Graduate Prosthodontics, College of Dentistry, University of Florida, Gainesville, FL, USA \\ ${ }^{3}$ Center for Implant Dentistry, College of Dentistry, University of Florida, Gainesville, FL, USA
}

\author{
${ }^{\mathrm{a} D D S}, \mathrm{PhD}$ \\ DDDS, MS \\ 'DMD, MS, FACP \\ 'BDS, MS \\ ePhD
}

\begin{abstract}
DOI: 10.25241/stomaeduj.2018.5(4).art.1

Purpose of the Study: Compare occlusal wear of PMMA DCL denture teeth under two different loads in vitro.

Materials \& Methods: Sixteen mandibular second premolars (SR Orthoplane DCL) with a flat occlusal surface (specimens) were worn by sixteen maxillary second premolar-antagonists (Ortholingual DCL). These teeth were subjected in a chewing simulator (CS-4, SD Mechatronik) up to 240,000 loading cylces at $19.6 \mathrm{~N}$ ( $\mathrm{LL} \approx$ full denture) and $68.6 \mathrm{~N}(\mathrm{HL} \approx$ implant-overdenture) and TC $\left(2,222 \times 5^{\circ} \mathrm{C}-55^{\circ} \mathrm{C}\right)$. Replicas of mandibular teeth were obtained at 0, 10,000;20,000;40,000; up to 240,000 cycles with polyvinyl-siloxane impressions and dental stone. Antagonist-replicas were made at baseline and at 240,000 cycles. The volumetric wear was determined with Geomagic after scanning replicas with a laser scanner. Linear regressions and ANOVA were used for statistical analysis.

Results: The wear rate of the HL-specimens was significantly higher than that of the LL-group ( $p$ $<0.0001$ ). The $L L$-wear rate became linear after 60,000 cycles and was calculated to be $0.182 \times 10^{-6}$ $\mathrm{mm}^{3} /$ stroke. The HL-wear rate was linear from 20,000 to 140,000 cycles and was $1.056 \times 10^{-6} \mathrm{~mm}^{3} /$ stroke, then up to 240,000 cycles $0.656 \times 10^{-6} \mathrm{~mm}^{3} /$ stroke. At 240,000 cycles the HL-group showed significantly higher antagonist-wear $(p<0.0001)$. The antagonists in both groups demonstrated higher wear than their opposing specimens $(p<0.08)$.

Conclusions: $\mathrm{HL}$ generated significantly higher wear of both the specimens and the antagonists. The antagonists showed higher wear than the specimens. As a clinical consequence one may expect more wear of denture teeth in implant supported overdentures than in full dentures. Keywords: wear, denture, PMMA, cross linked, in vitro.
\end{abstract}

\section{Introduction}

Estimates show that in the US the adult population in need of one or two complete dentures will increase from 35.4 million adults in the year 2000 to 37.9 million adults in 2020 [1]. Despite the fact that prevention is able to avoid tooth loss $[2,3]$ these numbers are very high. There are basically two reasons for this. First, the population demographics have changed dramatically. Based on US census statistics, there are substantial trends observed for the time period 1991 - 2020. The total adult population will increase significantly from 187 million to 245 million; adults aged 55 to 74 years will increase by $86 \%$ from $39,280,000$ to $73,099,000$ and senior adults 75 years and older will increase by $61 \%$, from $13,489,000$ to $21,835,000[4,5]$. Second, the population older than 55 did not profit much from the benefits of prevention [1], and finally the social structure $[6,7]$ combined with health care insurance being not mandatory has favored tooth extractions vs restorative dentistry. Thus, the aging population will bring with it an increase in the number of teeth lost [8]; projections for 2050 predict the number of edentulous people in the US at 8.6 million [6]. Life expectancy will continue to increase due to advances in the medical fields.

For over 100 years, complete maxillary and mandibular dentures have been the traditional standard of care for edentulous patients [9], in which patients still perceive improved treatment success in terms of increased prosthesis retention and stability in this treatment method [10]. However, many patients have limitations with stability and retention; over $50 \%$ of mandibular prostheses had such problems [11]. Edentulous patients have prosthodontic and physiologic limitations. With respect to physiology, significant amount of mechanoreception is compromised after teeth loss due to absence of the periodontal ligament, which contains sensory fibers. It leads to abnormal changes in magnitude, precision, and direction of occlusal load application [12]. Awad et al [13] reported that incorporating new dentures may result in improvements of overall satisfaction 
reported by patients, regarding aesthetics, comfort, and speech. On the other hand, for some patients, the incorporation of new dentures may not improve their function [13]. This confirms that there is a wide variety in the ability of edentulous patients to tolerate complete dentures $[13,14]$. Among elderly denture patients, $25 \%$ experienced pain when chewing and $41 \%$ needed more time for chewing. This can be explained with age related physiological changes, decreased motor control of the tongue, decreased biting force, and medication induced xerostomia [15]. People wearing full dentures have less than $20 \%$ of the masticatory performance of those with a natural dentition [16,17]. If a few teeth, preferably canines, are left and usable in the mandible, teeth supported overdentures can be incorporated, which means that complete dentures are supported by both edentulous ridges and the retained natural roots. This solution shows increased retention, stability, and comfort for the patients with increased quality of life [18]. With the introduction of titanium implants that osseointegrate in the 1970s [19-21] the way was open for implant supported overdentures with higher probability of success in the mandible when overdentures are supported by implants rather than tooth roots [22]. In the year 2002, the McGill consensus statement on overdentures declared that "Mandibular two-implant overdentures as first choice standard of care for edentulous patients [9] are based on an overwhelming evidence" [8]. This decision has been supported and the superiority of implant supported overdentures has been confirmed with systematic reviews $[23,24]$.

Removable complete dentures consist of denture bases, which contain mostly polymethyl methacrylate [25]. Their designs are patient-specific, made during the prostheses processing in dental laboratories. Denture teeth are the other component of complete dentures, in general, there are three different materials used to fabricate teeth by dental manufacturers. The ceramic type was first introduced in Europe in 1789, its use is limited nowadays due to difficulty in adjustment and potential fracture from the denture base [26], although they have favorable esthetics and wear resistance. Acrylic resin denture teeth were introduced in the 1940s, and they contain mostly polymethyl methacrylate (PMMA). They are more frequently used than ceramic teeth in removable prosthodontics [27], due to some advantages such as excellent fracture toughness, easy occlusal adjustment and high bond strength to the denture base [28]. Their previous generations showed problematic wear resistance [29]. There are four subgroups under PMMA teeth; a) conventional unfilled, b) inorganically filled, c) highly crosslinked, and d) double cross-linked (DCL), which has improved mechanical and physical properties [30]. Composite resin denture teeth were introduced in the 1980s. It is claimed that they have more favorable esthetics and wear resistance [30].

Some studies showed an increase in motor control and perception in removable implant-retained prostheses [31]. In patients with complete dentures, a mean chewing force was reported in one study
I Table 1. Ingredients of PMMA DCL denture teeth [60].

\begin{tabular}{cc}
\hline Ingredients & Weight \% \\
\hline Polymethyl methacrylate & $33-35$ \\
Dimethylacrylate & $5-7$ \\
Cross-linked PMMA & 59 \\
UDMA/PMMA fillers & 0 \\
Pigments & $<0.5$ \\
Initiators \& stabilizers & $<0.5$ \\
\hline
\end{tabular}

to be approximately 20 Newton [32], another study reported a mean chewing force of nearly 70 Newton in the mandibular implant-retained overdentures [33], indicating an overall increase of load on denture teeth within the studies' limitations.

Wear of acrylic resin teeth was reported in the literature. Wear is a phenomenon that occurs when two surfaces undergo a slipping movement under an applied load [34]. It is a complex, multifactorial process [35]. Abrasive wear occurs in natural and artificial teeth, it is the removal of material by the act of rubbing, cutting, or scraping [36]. Two-body abrasive wear occurs between denture teeth $[37,38]$, which is friction between two surfaces without an abrasive agent or medium present. The attritional wear resistance of restorative materials limits the service time of the restorations [39].

Nowadays, many edentulous patients are treated using removable complete dentures with PMMA $D C L$ denture teeth as a common choice, because of their better wear resistance [40]. In addition, there is an increased trend in patient acceptance of implant-retained overdentures. With a potential increase in motor control after implant treatment, it might be beneficial to know if the difference in chewing force will accelerate the wear of this type of popular artificial teeth. Therefore, the objective of this in vitro study was to compare the occlusal wear rate of the modern PMMA DCL denture teeth under two different loads. A low load simulated a mean chewing force in conventional complete dentures and a high load simulated a mean chewing force in implant-retained overdentures.

Null hypotheses:

- The in vitro wear of DCL PMMA denture teeth is independent of the chewing load;

- The in vitro wear of DCL PMMA denture teeth increases linearly with the number of chewing cycles.

\section{Materials and Methods}

DCL PMMA denture teeth (Ivoclar Vivadent, Schaan, Liechtenstein) were selected. Sixteen mandibular second premolars (SR Orthoplane DCL ML6, REF 565849, LOT UP0794) were used as specimens and sixteen maxillary second premolars (Ortholingual DCL LU6, REF 565736, LOT UP2255) were used as antagonists. The composition of these denture teeth is shown on Table 1. These teeth were placed 


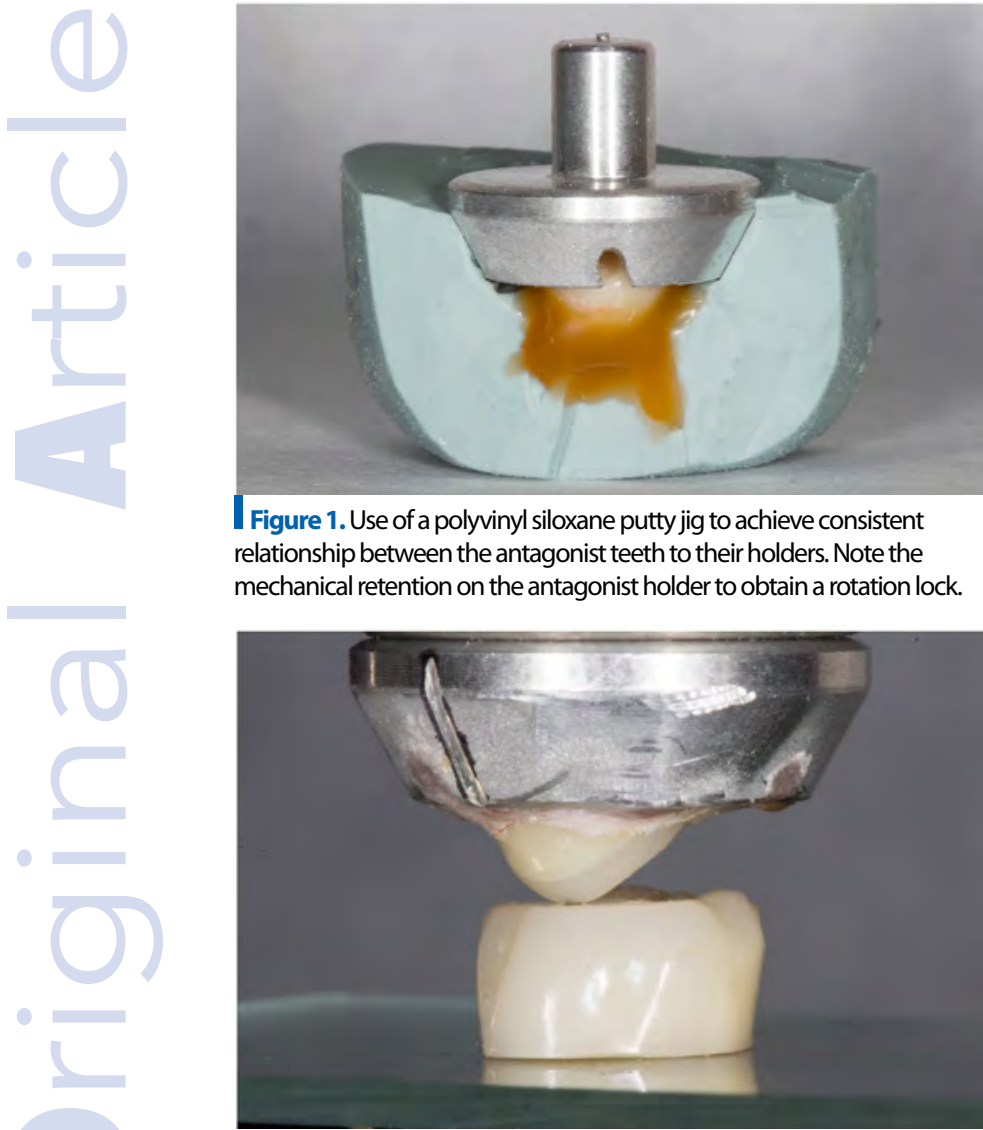

(a) A mounted antagonist tooth with its palatal cusp in contact with the center of a flat occlusal surface on a specimen tooth.

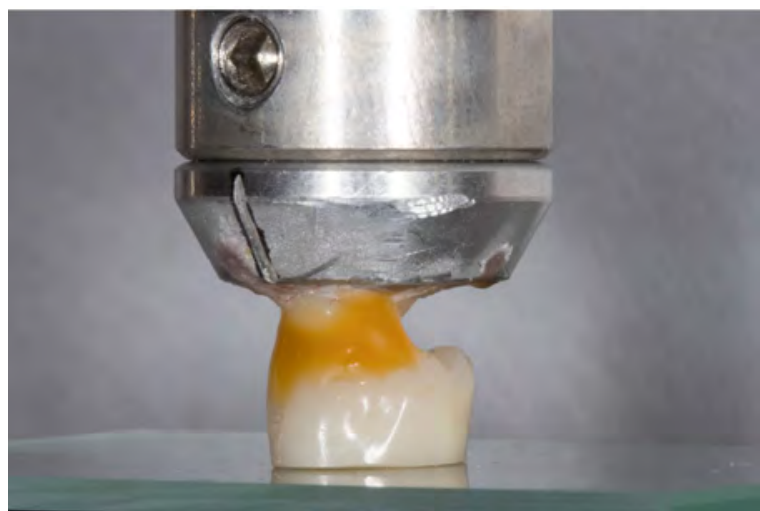

(b) A specimen tooth was stabilized onto its antagonist tooth using a dental stick wax.

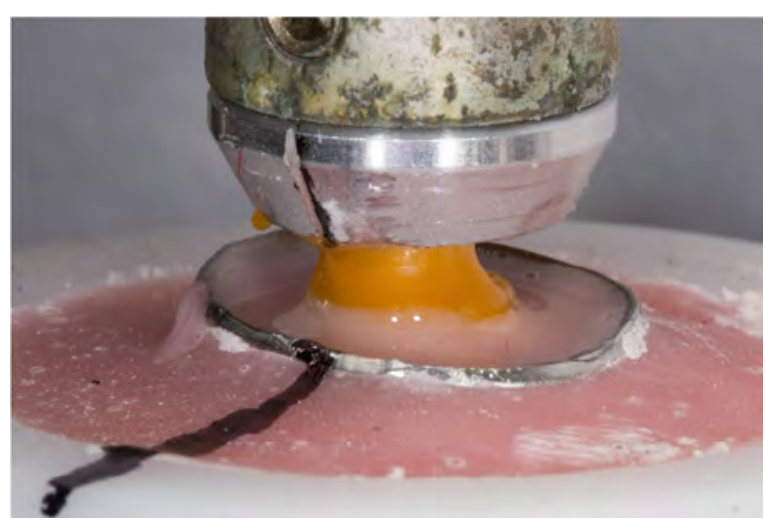

(c) Lowering the mouting jig arm to position specimen teeth into coldcuring acrylic resin.

I Figure 2. Mounting of specimen teeth $(a, b, c)$.

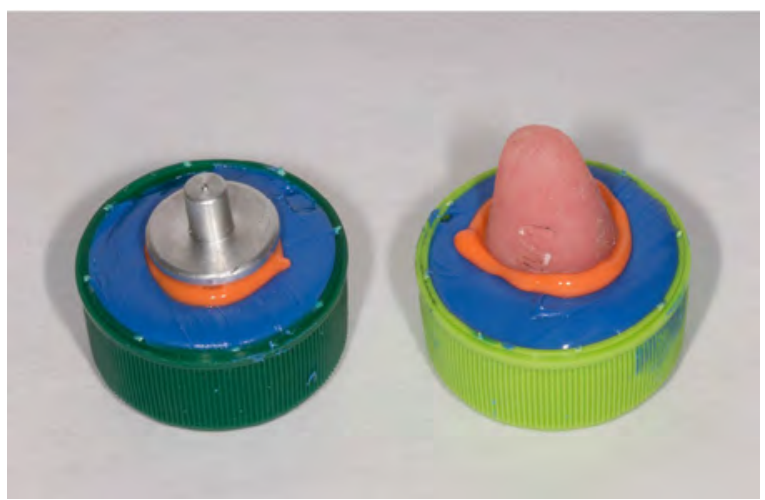

(a) Impression making of an antagonist tooth (left) and a specimen tooth (right).

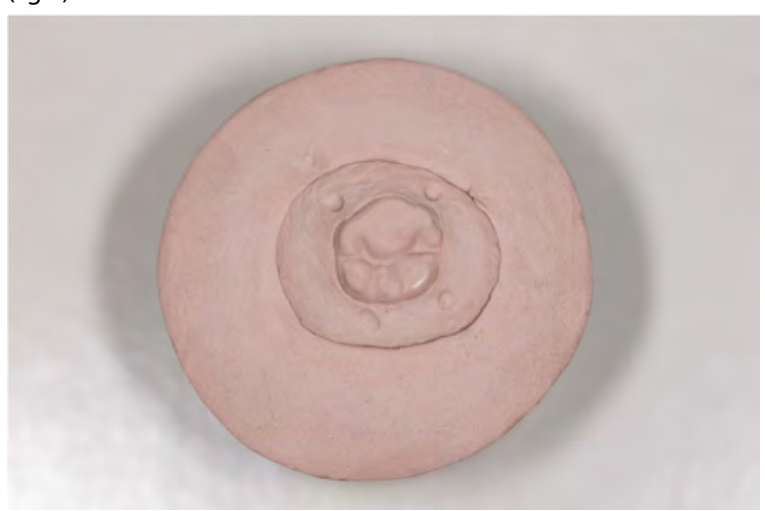

(b) A stone replica of a specimen tooth.

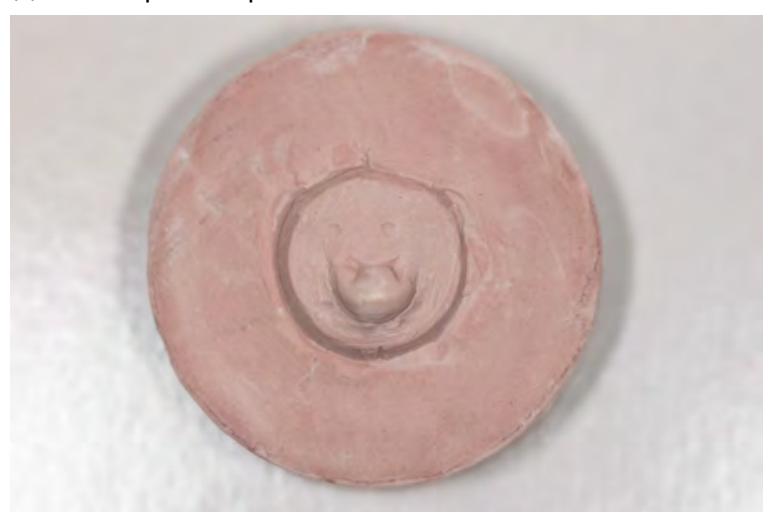

(c) A stone replica of an antagonist tooth.

I Figure 3. Impression making of specimens and antagonists $(a, b, c)$.

in a chewing simulator (CS-4, SD Mechatronik, Feldkirchen-Westerham, Germany) at two different loads:

1. 19.6 Newton (low-load group): 8 specimens and 8 antagonists

2. 68.6 Newton (high-load group): 8 specimens and 8 antagonists

The maxillary premolars (antagonists) were mounted with cold-curing acrylic resin (Pro Base Cold, Ivoclar Vivadent) onto antagonist metal holders, modified with a rotary instrument to achieve extra retention, air-abraded with aluminum oxide particles and conditioned with Monobond Plus (Ivoclar Vivadent). A polyvinyl siloxane putty jig (Virtual ${ }^{\circledR}$ XD Putty, Ivoclar Vivadent, Amherst, NY) was made after mounting the first antagonist in order to get consistent relationship between the antagonist teeth to their holders (Fig. 1). The antagonists were slightly tipped to position their palatal cusps at the highest point to be in contact with the specimens, their buccal cusps were shortened to 
be in level with the embedding medium. A mounting jig system was used to conveniently achieve specific occlusal relationship between those prepared antagonists and their opposing specimens outside the chewing simulator machine. It was aimed to have each palatal cusp in contact with the center of the monoplane mandibular premolar's buccal cusp. Every mandibular premolar was stabilized using a small amount of dental sticky wax to a mounted antagonist in the defined position, and then the assembly was lowered into an individualized specimen holder, loaded with cold-curing acrylic resin for embedding (Fig. 2). These metal holders had irregular designs, in order to prevent positional errors. When the setting became fully completed, a polyvinyl siloxane putty jig was made to securely support the assembly's upper and lower components, which contained a pair of denture teeth, and then they were moved into the chewing simulator. The occlusal relationship in each pair of teeth was verified before having definitive positioning inside the machine.

The specimens were mounted randomly into the 8 chambers of the chewing simulator and stressed mechanically and thermally at $1.2 \mathrm{~Hz}$ with horizontal movement of $0.7 \mathrm{~mm}$. Mechanical stresses were lowload $(19.6 \mathrm{~N})$ and high-load $(68.6 \mathrm{~N})$. Thermal stresses were introduced by cycling between $5{ }^{\circ} \mathrm{C}$ and $55^{\circ} \mathrm{C}$, dwell time was $30 \mathrm{~s}$ at each temperature with $15 \mathrm{~s}$ changing times for a total of 90 s per cycle. For 240,000 chewing strokes, there were 2,222 thermal cycles. Impressions of mandibular teeth were obtained before starting the experiment and after 10,000; 20,000; 40,$000 ; 60 ; 000 ; 80,000 ; 100,000 ; 120,000,140,000$, $160,000,180,000,200,000,220,000$, and 240,000 chewing strokes using polyvinyl siloxane impression materials (Virtual ${ }^{\circledR}$ XD Extra-Light Body and Virtual ${ }^{\circledR}$ XD Heavy Body, Ivoclar Vivadent). Impressions of antagonist teeth were made at baseline and after the end of the experiment only. The following impression technique was used: one step heavy body/wash using small plastic containers (plastic bottle caps) as impressions trays (Fig. 3). The impressions were poured using type IV dental stone (Silky-Rock, Whip Mix, Louisville, U.S.) after being boxed (Fig. 3).

\subsection{Quantification of wear}

Stone models of both specimens and antagonists were scanned using a laser scanner (Laserscanner LAS-20, SD Mechatronik). The amount of wear was calculated using a 3-D software (Geomagic Control, 3Dsystems, Rock Hill, SC, USA). With respect to the specimens, the periphery of each worn area (facet) on the flat buccal cusp surface was selected first to be used as a reference. Then all the surrounding data (non-worn surfaces) were deleted, the depression inside the facet was filled using the "fill command", generating a flat surface coronally at the same level with the non-worn borders, the last step was to volumetrically measure the space within the worn area, which represented the amount material loss in cubic millimeter (Fig. 4). As for the antagonists, 3-D images of both the baseline and the final wear were superimposed using four reference points. Circular trimming was done for the superimposed models to

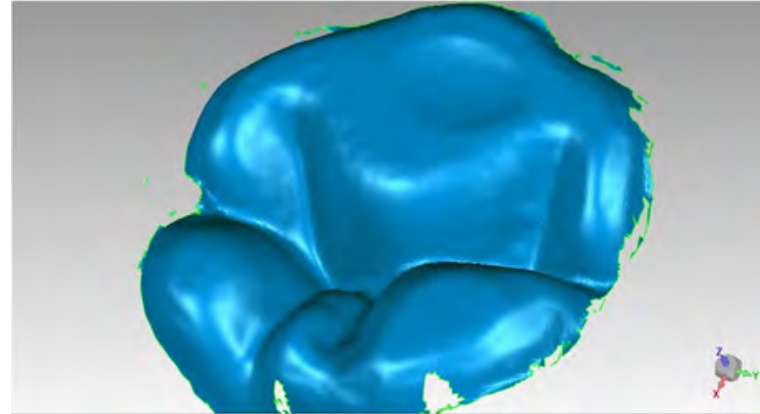

(a) A 3-D image of a specimen tooth showing a wear facet on the monoplane cusp.

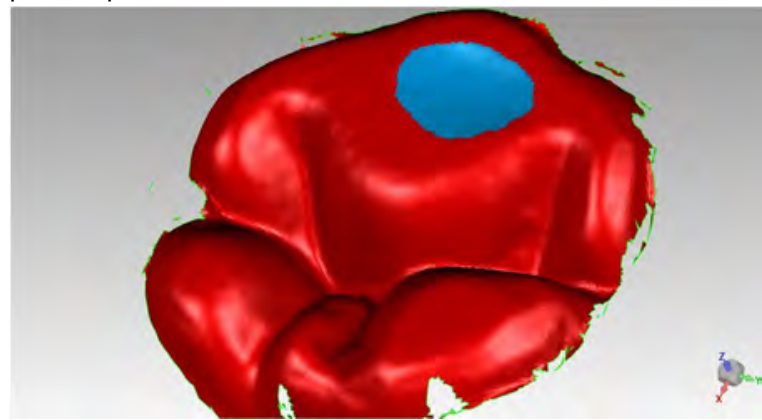

(b) Selection of the facet and isolating the non-worn surfaces (in red), which were deleted subsequently.

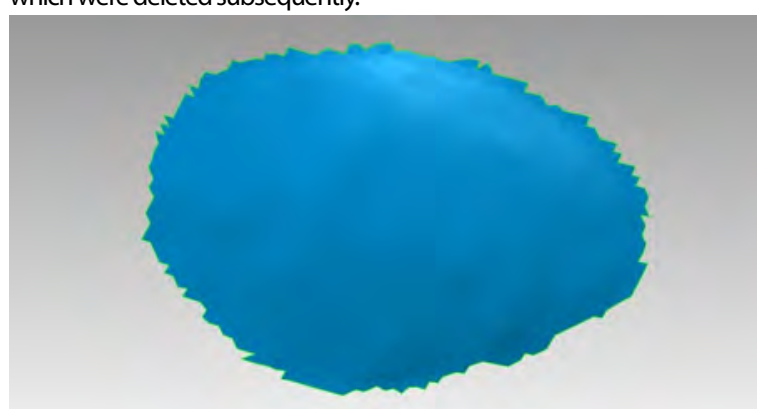

(c) Close-up view: the facet area with its non-worn periphery after deleting the surrounding surfaces.

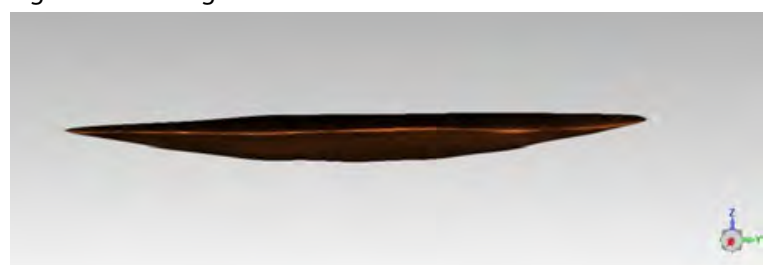

(d) Lateral view: the space within the facet was filled in creating a flat surface above in level with the non-worn periphery; it resembled the surface before starting wear simulation.

I Figure 4. Quantification of wear in the specimen teeth (a-d).

delete all data that did not have any changes in the final wear image inferior to the worn cusp's borders. After isolating the superimposed worn and nonworn cusp tips the non-worn periphery was used as a reference to fill the space inside the cusp tip, volumetric measurements were taken in each model. The last step was to calculate the difference between them to yield in the material loss in cubic millimeter.

\subsection{Evaluation of wear pattern}

Surface details of the wear areas of both selected specimens and antagonists were inspected after completion of chewing rounds using digital microscopy (VH-1000 series, KEYENCE, Itasca, IL, U.S.) at $100 x$ magnification, in order to evaluate the wear pattern. 


\subsection{Statistical analysis}

Linear regression (SAS 9.4) of the amount of wear in volume against the number of chewing cycles was used to determine the wear rate of each specimen tested. The statistical difference between the mean wear rates of the two loading groups was determined by linear regression, ANOVA, and Tukey test. The statistical differences of the mean of total volume of wear of antagonists and the specimens as influenced by the loading were determined with the T-tests.

\section{Results}

The experimental data show that there is a linear relationship between the cumulative wear volume and the number of cycles ( $R^{2}>95 \%$ for all specimens), excluding the first reading of the high-load group and the first two readings of the low-load group (Fig. 5). In addition, the high-load group appears to have two segments with distinct linear relation intersecting at 140,000 cycles. ANOVA and Tukey test showed significant differences $(p<0.0001)$ between the two segments $(68.6 \mathrm{~N}-1$ and $68.6 \mathrm{~N}-2)$ of the high load group and between the high load group and the low load group (Fig. 5, Tab. 2). For the high load group two separate wear rates were calculated: from 20,000 to 140,000 cycles it was $1.056 \times 10^{-6} \mathrm{~mm}^{3} / \mathrm{stroke}$, then up to 240,000 cycles $0.656 \times 10^{-6} \mathrm{~mm}^{3} / \mathrm{stroke}$. The wear rate of the low load group was $0.182 \times 10^{-6} \mathrm{~mm}^{3} /$ stroke (Tab. 2).

The wear of the antagonists at the end of the experiment $(240.000$ cycles) is shown in Fig. 6 . As for the sample teeth, there is a significant difference between the high load and the low load group. Comparing the sample wear with the antagonist wear at 240.000 cycles T-tests revealed statistical differences $(p<0.001)$ between low-load group and either segment of high-load group, and between the two segments of the high-load group (Tab. 3).

The microscopic images showed comparable wear patterns among the two groups' specimens, unlike that of the antagonists, which showed coarse and irregular surface texture in the low-load group as compared to the high-load group (Figs. $7 \& 8$ ).

\section{Discussion}

PMMA denture teeth have been used more frequently than other types due to favorable procedural and chemical properties [41]. Greater significance is added in studies when a commonly used material is selected for testing. The occlusal surface wear is a result of the combination of impact wear and sliding wear during process of mastication [42,43]. Progressive denture teeth wear results in insufficient posterior teeth support and consequently may lead to changes in the vertical and horizontal yaw relations and may cause functional and aesthetical impairments $[44,45]$. In order to assess the wear of a dental material such as denture teeth, it is advised to use impact and sliding as both occur on teeth surfaces during mastication. Denture teeth are used for edentulous patients, who have a reported mean chewing force of nearly $20 \mathrm{~N}$ wearing full dentures [32], and a mean chewing force

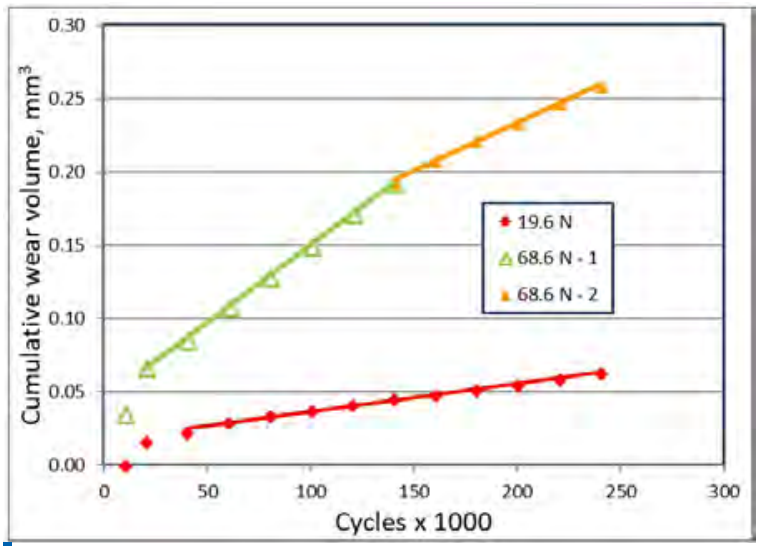

Figure 5. Mean wear volume as function of loading cycles. The high load group exhibits two segments (1 \&2) linear relationship and the straight line represents the best fit curve of the linear regression. $(p<0.0001)$.

I Table 2. ANOVA and Tukey test for both segments of high load wear and the low load wear of the specimens. Dependent Variable: wear rate.

\begin{tabular}{|c|c|c|c|c|c|}
\hline Source & DF & $\begin{array}{c}\text { Sum of } \\
\text { Squares }\end{array}$ & $\begin{array}{l}\text { Mean } \\
\text { Square }\end{array}$ & F Value & $\operatorname{Pr}>F$ \\
\hline Model & 2 & 3.05751734 & 1.52875867 & 116.84 & $<.0001$ \\
\hline Error & 21 & 0.27476608 & 0.01308410 & & \\
\hline \multirow{3}{*}{$\begin{array}{c}\text { Corrected } \\
\text { Total }\end{array}$} & 23 & 3.33228342 & & & \\
\hline & & R-Square & Coeff Var & $\begin{array}{l}\text { Root } \\
\text { MSE }\end{array}$ & $\begin{array}{l}\text { CYCLE } \\
\text { Mean }\end{array}$ \\
\hline & & 0.917544 & 18.10987 & 0.114386 & 0.631621 \\
\hline Source & DF & Anova SS & $\begin{array}{l}\text { Mean } \\
\text { Square }\end{array}$ & F Value & $\operatorname{Pr}>\mathrm{F}$ \\
\hline LOAD & 2 & 3.05751734 & 1.52875867 & 116.84 & $<.0001$ \\
\hline $\begin{array}{c}\text { Tukey } \\
\text { Grouping }\end{array}$ & Mean & $\mathbf{N}$ & LOAD (N) & & \\
\hline A & 1.05603 & 8 & 68.6 & & \\
\hline B & 0.65607 & 8 & 68.6 & & \\
\hline C & 0.18277 & 8 & 19.6 & & \\
\hline
\end{tabular}

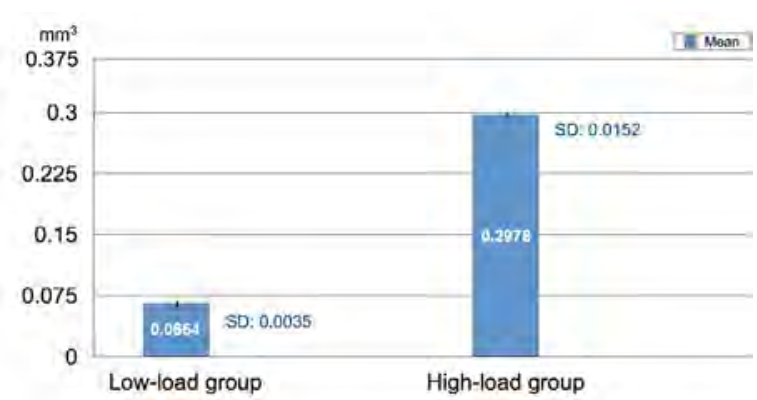

I Figure 6. Wear of the antagonists in both groups (Mean $\pm S D), p<0.001$.

I Table 3. Total wear volume (mean $\pm \mathrm{SD}$; in $\mathrm{mm}^{3}$ ) at the end of the experiment. Different capital superscript letters show significant differences for columns and different low letters show significant differences for rows $(p<0.001)$.

\begin{tabular}{ccc}
\hline \multirow{2}{*}{ Type of surface } & \multicolumn{2}{c}{ Loading cycle } \\
\cline { 2 - 3 } & $\mathbf{1 9 . 6 \mathrm { N }}$ & $\mathbf{6 8 . 6} \mathrm{N}$ \\
\hline Antagonist & $0.065 \pm 0.004^{\mathrm{Aa}}$ & $0.298 \pm 0.015^{\mathrm{Ab}}$ \\
Specimen & $0.063 \pm 0.002^{\mathrm{Ba}}$ & $0.259 \pm 0.090^{\mathrm{Bb}}$ \\
\hline
\end{tabular}

of nearly $70 \mathrm{~N}$ with overdentures [33]. We assume that these values may reflect most clinical subjects, and can be used in chewing simulation studies.

A large number of chewing simulators have been used to determine in vitro wear of acrylic resin denture teeth [46-49]. In the present study the denture teeth were subjected to two-body wear, as it was reported in the literature [50-52]; it simulates the type of wear that occurs in full dentures with bilaterally balanced occlusion [51]. With respect to the selection of chewing cycles number, a wear simulation study 

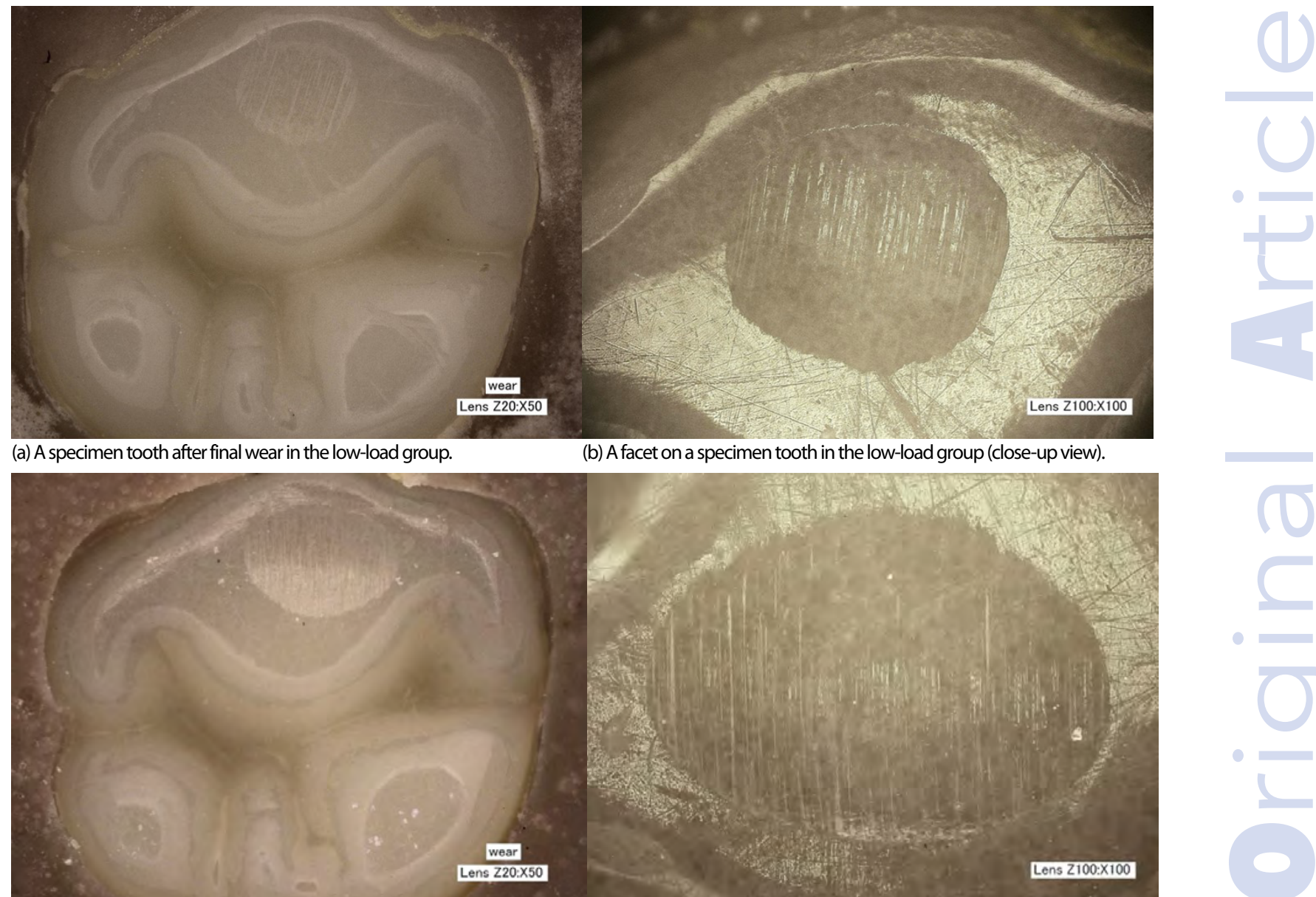

(d) A facet on a specimen tooth in the high-load group (close-up view).

I Figure 7. Microscopic digital images of specimen teeth in both groups a, b, c\&d).

of IPN PMMA denture teeth had wear results after 200,000 chewing cycles [53] comparable to 1-year clinic follow-up results with the same material in two in vivo studies [54,55]. Thus, Coffey et al [53] assumed that the amount of wear occurring at 200,000 cycles would correspond to approximately 1 year of clinical function. Regarding the selection of fluid, distilled water was proved as a suitable intermediate medium, it did not have a significant difference with respect to mechanical properties of enamel and denture-base materials when compared to human saliva $[56,57]$.

The selection of both specimens and antagonists denture teeth from the same material was done to simulate clinical conditions. The antagonist's material substantially influenced the wear rates in two-body wear [58]. In the present study, denture teeth with flat occlusal surfaces were used to simplify the wear analysis process. Measuring and interpreting the wear facet on a flat surface is more predictable than determining the wear on a complex occlusal surface with possibly more than one wear facet. Furthermore, it allowed comparisons with other studies using a similar approach [51]. When specimens with flat surfaces were exposed to antagonists from the same material, wear results were close to that of denture teeth's clinical wear [59]. Type IV low expansion dental stone replicas of denture teeth were produced after making polyvinyl siloxane impressions to investigate wear using a laser scanner, this method was considered accurate and reliable in other studies [59-61]. Furthermore, we had experienced distortions of the flat surface from wear facets scanned directly from ceramic discs [62]. The interpretation was that the laser beam, slightly entering a translucent surface was interacting with the material differently at an edge than on a regular surface. Therefore, for the present study the replica technique was preferred, where this phenomenon cannot happen with a stone surface.

The results of the present study showed significant differences in the wear rate between the low-load and the high-load groups for the specimens (Fig. 5) and the antagonists as well (Fig. 6). Mean wear rate of the high-load group specimens was 5.8 times greater before 140,000 cycles and 3.6 times greater after that turning point than the other group. As for their antagonists' mean wear rate, it was also greater by factor of 4.6. The linear regression analysis of the specimens wear rate showed an overall straightline data in both groups, indicating approximately consistent relationship between number of cycles and amount of wear. No wear was detected in the low-load group until 10,000 chewing strokes, which might either show the lower limit of wear detection of this method or demonstrate favorable short-term wear resistance.

There are some possible explanations for the shift in the high-load group's specimens wear rate after 


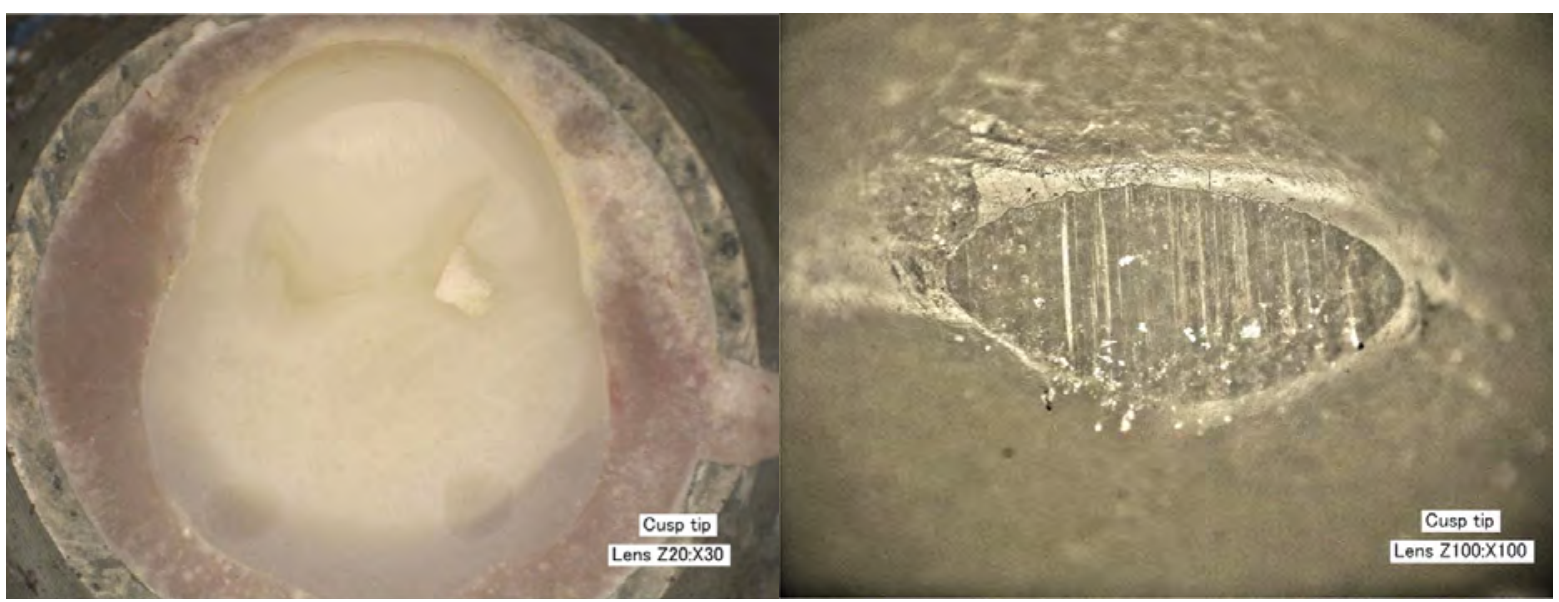

(a) An antagonist tooth after final wear in the low-load group.

(b) Worn palatal cusp tip after final wear in the low-load group (close-up view).

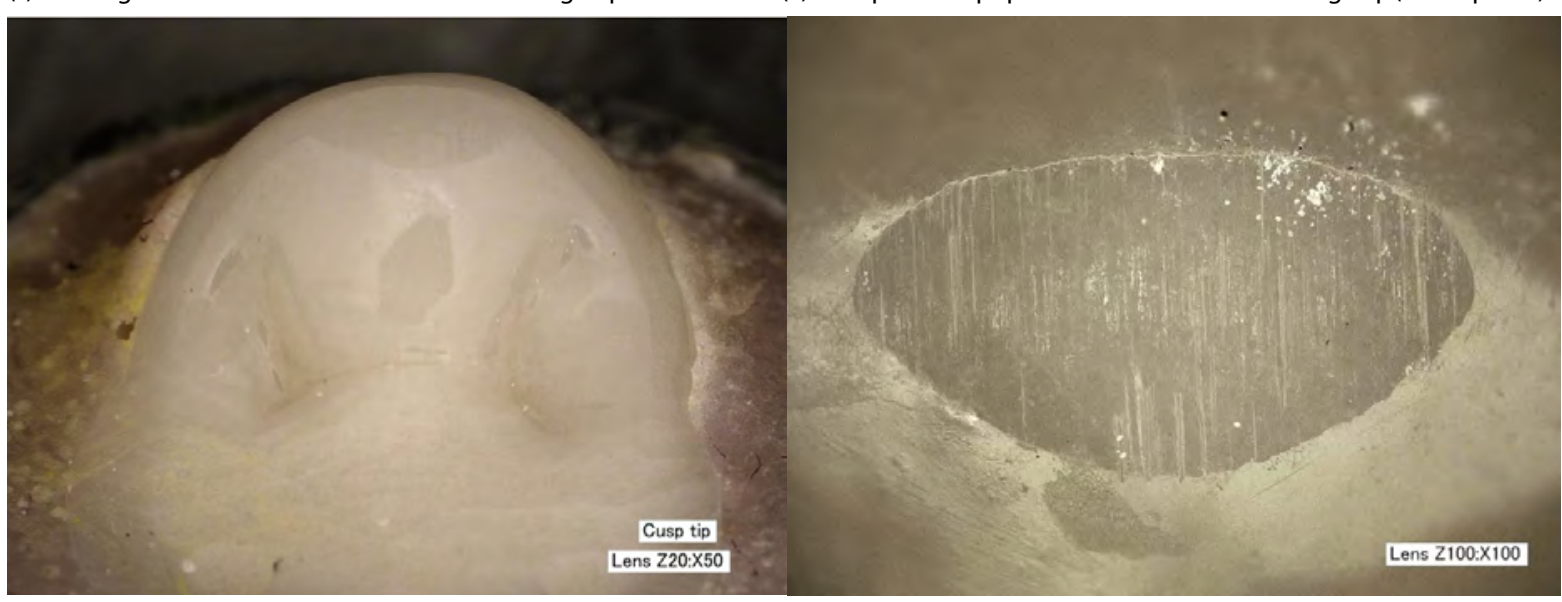

(c) An antagonist tooth after final wear in the high-load group.

(d) Worn palatal cusp tip after final wear in the low-load group (close-up view).

I Figure 8. Microscopic digital images of antagonist teeth in both groups (a, b, c \& d).

140,000 chewing strokes. Upon removal of fillers in the specimens due to the fatigue process of the filler/ matrix during lateral movement, the antagonists became rough, causing accelerated wear [59]. The enamel layer's ingredients of the PMMA denture teeth might have different mechanical properties than that of dentin layer [25], it is possible that dentin layers of specimens and/or antagonists were exposed at around 140,000 strokes. The influence of the antagonist shape on wear rate of their opposing surfaces was reported, a ball-shape stylus generated significantly less wear on PMMA denture teeth than a conical ceramic stylus as it created less fatigue stress $[59,63,64]$. In the present study, more flattened antagonist's cusps appeared in the high-load group. We recommend using high-resolution microscopy to assess the ultrastructure of the specimens after each chewing round, which might help to detect possible differences in wear pattern. The difference may be due to the measuring technique as well. In the high load group some of the wear facets were extended slightly beyond the flat surface with the result that some of the volume was missing due to the fact that the flat surface was used as a reference.

The specimens' wear results were compared to previously reported data. One in vitro study showed significantly greater wear rate after 100,000 strokes [51] as compared to the low-load group in the present study, it might be caused by the abrasive nature of aluminum oxide antagonists and the greater chewing load they used (40 N) [51]. A 1-year clinical study showed a comparable result to the high-load group of the present study after 240,000 strokes, assuming the average number of annual chewing strokes is close to the suggested rate [65]. The results of the present study also support those from an in vitro study, which had steatite balls as antagonists, the researchers used $49 \mathrm{~N}$ chewing load [52], and their reported values were in between those of our low-load group and high-load group at both 120,000 and 240,000 strokes. Wear resistance is an important physical property of removable denture teeth $[48,66]$. Clinical problems were detected such as loss of vertical dimension, loss of masticatory efficiency, faulty teeth relationship that could affect patients and dental practice [11,44,67]. The previous generations of PMMA denture teeth had poor wear performance, as was detected in an in vitro three-body wear assessment for non-DCL PMMA teeth [29]. On the contrary, PMMA DCL denture teeth showed higher in vitro wear resistance than the conventional type $[30,68]$. With respect to the clinical wear assessment, patient-related factors should be considered, since there are differences among individuals in muscle activity, duration of dentures wear, presence or absence of para-functional habits and abrasiveness of food [65]. According to a clinical study, higher wear was detected in the implant-retained overdentures [33], this finding is in 
agreement with the present study, since the highload group had greater wear.

There are only a few data about wear patterns of denture teeth. One in vitro study that had scanning electron microscopy (SEM) evaluation for PMMA DCL teeth opposed by the same tooth type using $30 \mathrm{~N}$ load after 100,000 cycles [59]. A direct comparison with these data is difficult, we used digital light microscopy vs SEM being used by Heintze et al 2012 [59]. In one group Heitze et al [59] used antagonists of the same material as the worn surface, however different diameters, different load $(30 \mathrm{~N})$ and $3 \mathrm{~mm}$ sliding distance vs $0.7 \mathrm{~mm}$ in the present study. The wear pattern of the DCL specimens in both studies seems to be comparable, showing uniformity with parallel fine grooves.

\section{Conclusion}

Modern PMMA DCL denture monoplane mandibular premolars were used as specimens opposed by semianatomic maxillary premolars as antagonists in a wear simulation experiment, with the chewing load as a variable factor.

Within the limitations of this study:

- Significantly greater wear of both the specimens and the antagonists was detected when a chewing load of $68.6 \mathrm{~N}$ (high-load group) was used as compared to a load of $19.6 \mathrm{~N}$ (low-load group);

- Higher wear rate of the antagonists was detected as compared to the specimens in both groups;

- In the high-load group, higher wear rate of the specimens was detected in the first 140,000 chewing cycles as compared to the subsequent 140,000 cycles. As a clinical consequence one may expect more wear of denture teeth in implant supported overdentures than in full dentures.

\section{Author Contributions}

JFR: Idea, experimental design, wrote final manuscript. AAN: Performed the experiment as part of the MS requirements, wrote initial manuscript. WM: experimental design, proofread manuscript. NA: supported experimental phase and data production. CS: statistical analysis, proofread manuscript.

\section{Acknowledgement}

The authors thank Ivoclar Vivadent for donating the materials.

\section{References}

1. Turkilmaz I, Company AM, McGlumphy EA. Should edentulous patients be constrained to removable complete dentures? The use of dental implants to improve the quality of life for edentulous patients. Gerodontology. 2010;27(1): 3-10. [Full text links] [PubMed] Google Scholar (120)

2. Roulet J-F, Zimmer S. Prophylaxe und Präventivzahnmedizin. Stuttgart, Germany: Georg Thieme Verlag, 2003. Google Scholar (21)

3. Axelsson P, Nyström B, Lindhe J. The long term effect of a plaque controlprogram on tooth mortality, caries and periodontal disease in adults. J Clin Periodontol. 2004;31(9): 749-757.

[Full text links] [PubMed] Google Scholar (803) Scopus (404)

4. U.S. Bureau of Census. Statistical Abstract of the United States:
1996. 116th edition. Washington DCUS. Bureau of Census 1996. p 15, Tab. II, No 14

5. U.S. Bureau of Census. Statistical Abstract of the United States: 1996. 116th edition. Washington DCUS. Bureau of Census 1996. p 17, Tab II No 17.

6. Slade GD, Akinkugbe AA, Sanders AE. Projections of US Edentulism prevalence following 5 decades of decline. J Dent Res. 2014;93(10): 959-965.

[Full text links] [Free PMC Article] [PubMed] Google Scholar (106) Scopus (61)

7. Dye BA, Thornton-Evans G, Li X, lafolla TJ. Dental caries and tooth loss in adults in the United States, 2011-2012. NCHS Data Brief No. 197, 2015.

[Full text links] [PubMed] Google Scholar (75) Scopus (42)

8. Feine JS, Carlsson GE, editors. Implant overdentures. The standard of care for edentulous patients. Chicago, IL: Quintessence; 2003.

Google Scholar (27)

9. Feine JS, Carlsson GE, Awad MA, et al. The McGill consensus statement on overdentures. Mandibular two-implant overdentures as first choice standard of care for edentulous patients. Gerodontology. 2002;19(1): 3-4. [Full text links] [PubMed] Google Scholar (379) Scopus (140)

10. Burns DR, Unger JW, Elswick RK Jr, Beck DA. Prospective clinical evaluation of mandibular implant overdentures: Part I - Retention, stability, and tissue response. J. Prosthet. Dent.1995;73(4): 354-363.

[Full text links] [PubMed] Google Scholar (230) Scopus (102)

11. Redford M, Drury TF, Kingman A, Brown $\sqcup$. Denture use and the technical quality of dental prostheses among persons 1874 years of age: United States, 1988-1991. J Dent Res. 1996;75 Spec No: 714-725.

[Full text links] [PubMed] Google Scholar (152) Scopus (69)

12. Klineberg I, Murray G. Osseoperception: sensory function and proprioception. Adv Dent Res. 1999;13: 120-129.

[Full text links] [PubMed] Google Scholar (103) Scopus (30)

13. Awad MA, Lund JP, Dufresne E, Feine JS. Comparing the efficacy of mandibular implant-retained overdentures and conventional dentures among middle-aged edentulous patients: satisfaction and functional assessment. Int $J$ Prosthodont. 2003;16(2): 117-122. [PubMed] Google Scholar (309) Scopus (164)

14. Boerrigter EM, Stegenga B, Raghoebar GM, Boering G. Patient satisfaction and chewing ability with implant-retained mandibular overdentures: a comparison with new complete dentures with or without preprosthetic surgery. J Oral Maxillofac Surg. 1995;53(10): 1167-1173.

[Pub Med] Google Scholar (145) Scopus (84)

15. Smith JM, Sheiham A. How dental conditions handicap the elderly. Community Dent Oral Epidemiol. 1979;7(6): 305-310. [Full text links] [PubMed] Google Scholar (193)

16. Kapur KK, Soman SD. Masticatory performance and efficiency in denture weares. J Prosthet Dent. 1964;14(4): 687-694. [PubMed] Google Scholar (210)

17. Heath MR. The effect of maximum biting force and bone loss upon masticatory function and dietary selection of the elderly. Int Dent J. 1982;32(4): 345-356.

[PubMed] Google Scholar (225) Scopus (121)

18. Dodge CA. Prevention of complete denture problems by use of "overdentures". J Prosthet Dent. 1973;30(4 Pt 1): 403-411. [PubMed] Google Scholar (58) Scopus (24)

19. Brånemark PI, Hansson $\mathrm{BO}$, Adell R, et al. Osseointegrated implants in the treatment of the edentulous jaw. Experience from a 10-year period. Scand J Plast Reconstr Surg. 1977;16: 1-132. [PubMed] Google Scholar (2751) Scopus (1927)

20. Schroeder A, Pohler O, Sutter F. [Tissue reaction to an implant of a titanium hollow cylinder with a titanium surface spray layer]. [Article in German]. Schweiz Mschr Zahnheilk. 1976;86(7): 713-727.

[PubMed] Google Scholar (134) Scopus (0)

21. Schroeder A, Sutter F, Ledermann PD, Stich H. [Current experience with the ITI double hollow cylinder implant type $\mathrm{K}$. Internationales Team für orale Implantologie].[Article in German]. Schweiz Mschr Zahnheilk. 1984;94(6):503-510. [PubMed] Google Scholar (3) Scopus (0)

22. Mericske-Stern R, Steinlin Schaffner T, Marti P, Geering AH. Peri-implant mucosal aspects of ITI implants supporting overdentures. A five-year longitudinal study. Clin Oral Implants Res. 1994;5(1): 9-18.

[Full text links] [PubMed] Google Scholar (370) Scopus (157)

23. Thomason JM, Kelly SA, Bendkowski A, Ellis JS. Two implant retained overdentures--a review of the literature supporting the McGill and York consensus statements. J Dent. 2012;40(1): 22-34.

[Full text links] [PubMed] Google Scholar (175) Scopus (102)

24. Boven GC, Raghoebar GM, Vissink A, Meijer HJ. Improving masticatory performance, bite force, nutritional state and patient's satisfaction with implant overdentures: a systematic 
review of the literature. J Oral Rehab. 2015;42(3): 220-233. [Full text links] [PubMed] Google Scholar (76) Scopus (42)

25. Heintze SD, Monreal D, Rousson V. Fatigue resistance of denture teeth. J Mech Behav Biomed Mater. 2016;53: 373-383. [Full text links] [PubMed] Google Scholar (10)

26. Marchack BW, Yu Z, Zhao XY, White SN. Adhesion of denture tooth porcelain to heat-polymerized denture resin. J Prosthet Dent. 1995;74(3): 242-249.

[Full text links] [PubMed] Google Scholar (30) Scopus (16)

27. Ghazal M, Kern M. Wear of denture teeth and their human enamel antagonists. Quintessence Int 2010;41(2): 157-163. [Full text links] [PubMed] Google Scholar (22) Scopus (10)

28. Ekfeldt A, Oilo G. Wear mechanisms of resin and porcelain denture teeth. Acta Odontol Scand. 1989;47(6): 391-399. [PubMed] Google Scholar(36) Scopus(29)

29. Winkler S, Monasky GE, Kwok J. Laboratory wear investigation of resin posterior denture teeth. J Prosthet Dent. 1992;67(6): 812-814.

[Full text links] [PubMed] Google Scholar (53) Scopus (24)

30. Suzuki S. In vitro wear of nano-composite denture teeth. $J$ Prosthodont. 2004;13(4): 238-243.

[Full text links] [PubMed] Google Scholar (102) Scopus (53)

31. Abarca M, van Steenberghe D, Malevez C, et al. Neurosensory disturbances after immediate loading of implants in the anterior mandible: an initial questionnaire approach followed by a psychophysical assessment. Clin Oral Investig. 2006;10(4): 269-277. [Full text links] [Free PMC Article] [PubMed] Google Scholar (73) Scopus (40)

32. Michael CG, Javid NS, Colaizzi FA, Gibbs CH. Biting strength and chewing forces in complete denture wearers.J Prosthet Dent. 1990;63(5): 549-553.

[Full text links] [PubMed] Google Scholar (118) Scopus (67)

33. Fontijn-Tekamp FA, Slagter AP, Van Der Bilt A, et al. Biting and chewing in overdentures, full dentures, and natural dentitions. JDent Res. 2000;79(7): 1519-1524. [Full text links] [PubMed] Google Scholar (638) Scopus (366)

34. Sulong MZ, Aziz RA. Wear of materials used in dentistry: a review of the literature. J Prosthet Dent. 1990;63(3): 342-349. [Full text links] [PubMed] Google Scholar (151) Scopus (70)

35. Burwell JR. Survey of possible wear mechanisms. Wear. 1957;1(2): 119-141.

Google Scholar (389) Scopus (168)

36. Ferracane JL. Materials in dentistry: principle and application. Philadelphia: J.B. Lippincott, 1995; 293-311. Google Scholar (318)

37. Harrison A, Lewis TT. The development of an abrasion testing machine for dental materials. J Biomed Mater Res. 1975;9(3): 341-353.

[PubMed] Google Scholar (118

38. Harrison A, Huggett R. Measuring the rate of wear of artificial teeth in complete dentures. J Prosthet Dent. 1975;33(6): 615-619.

[Full text links] [PubMed] Google Scholar (14) Scopus (8)

39. Kern M, Strub JR, Lü XY. Wear of composite resin veneering materials in a dual-axis chewing simulator. J Oral Rehabil. 1999;26(5): 372-378.

[Full text links] [PubMed] Google Scholar (205) Scopus (138)

40. Reis KR, Bonfante G, Pegoraro LF, et al. In vitro wear resistance of three types of polymethyl methacrylate denture teeth. $J$ Appl Oral Sci. 2008;16(3): 176-180.

[Full text links] [Free PMC Article] [PubMed] Google Scholar (31) Scopus (18)

41. Stober T, Henninger M, Schmitter $M$, et al. Three-body wear of resin denture teeth with and without nanofillers. J Prosthe Dent. 2010;103(2): 108-117.

[Full text links] [PubMed] Google Scholar (34) Scopus (14)

42. Kim SK, Kim KN, Chang IT, Heo SJ. A study of the effects of chewing patterns on occlusal wear. J Oral Rehabil. 2001;28(11): 1048-1055.

[Full text links] [PubMed] Google Scholar (73) Scopus (46)

43. Mair LH, Strlarski TA, Vowles RW, Loyd CH. Wear: mechanisms, manifestations and measurement. Report of a workshop. $J$ Dent. 1996;24(1-2): 141-148.

[Full text links] [PubMed] Google Scholar (386) Scopus (209)

44. Rammelberg P, Pospiech P, Gernet W, et al. [Etiologic factors of disk displacement in the TMJ]. [Article in German]. Dtsch Zahnärztl Z. 1996;21:211-218.

Google Scholar (365)

45. Yip KH, Smales RJ, Kaidonis JA. Differential wear of teeth and restorative materials: clinical implications. Int J Prosthodond. 2004;17(3): 350-356

[PubMed] Google Scholar (115) Scopus (57)

46. Cornell JA, Jordan JS, Ellis S, Rose EE. A method of comparing the wear resistance of various materials used for artificial teeth. J Am Dent Assoc. 1957;54(5): 608-614.

[Full text links] [PubMed] Google Scholar (56) Scopus (19)

47. Satoh Y, Nagai E, Maejima K, et al. Wear of denture teeth by use of metal plates. Part 2: Abrasive wear of posterior teeth. $J$
Nihon Univ Sch Dent. 1992;34(1): 16-27.

[PubMed] Google Scholar (0) Scopus (9)

48. Zeng J, Sato Y, Ohkubo C, Hosoi T. In vitro wear resistance of three types of composite resin denture teeth. J Prosthet Dent. 2005;94(5): 453-457.

[Full text links] [PubMed] Google Scholar (79) Scopus (42)

49. ISO/TS 14569-2: 2001 (en). Dental materials-Guidance on testing or wear-part 2. Wear by two- and three body contact. https://www.iso.org/obp/ui/\#iso:std:iso:ts:14569:-2:ed1:v1:en

50. Kunzelmann KH1, Bürkle V, Bauer C. Two-body and threebody wear of glass ionomer cements. Int J Paediatr Dent. 2003;13(6): 434-440. PMID:

[Full text links] [PubMed] Google Scholar (24) Scopus (8)

51. Stober T, LutzT, Gilde H, Rammelsberg P. Wear of resin denture teeth by two-body contact. Dent Mater. 2006;22(3): 243-249.

[Full text links] [PubMed] Google Scholar (90) Scopus (51)

52. Ghazal M, Steiner $M$, Kern $M$. Wear resistance of artificial denture teeth. Int J Prosthodont. 2008:21(2): 166-168. [PubMed] Google Scholar (25) Scopus (60)

53. Coffey JP, Goodkind RJ, DeLong R, Douglas WH. In vitro study of the wear characteristics of natural and artificial teeth. $J$ Prosthet Dent. 1985;54(2): 273-280.

[Full text links] [PubMed] Google Scholar (85) Scopus (41)

54. Harrison A. Clinical results of the measurement of occlusal wear of complete dentures. J Prosthet Dent. 1976;35(5): 504511. [Full text links] [PubMed] Google Scholar (34) Scopus (23)

55. 55.Ogle RE, David LJ, Ortman HR. Clinical wear study of a new tooth material: Part II. J Prosthet Dent. 1985;54(1): 67-75. [Full text links] [PubMed] Google Scholar (48) Scopus (27)

56. Douglas WH, Sakaguchi RL, DeLong R. Frictional effects between natural teeth in an artificial mouth. Dent Mater. 1985;1(3): 115-119.

[Full text links] [PubMed] Google Scholar (46) Scopus (31)

57. Al-Mulla MA, Murphy WM, Huggett R, Brooks SC. Effect of water and artificial saliva on mechanical properties of some denture-base materials. Dent Mater. 1989;5(6): 399-402. [Full text links] [PubMed] Google Scholar (27) Scopus (17)

58. Abe Y, Sato Y, Akagawa Y, Ohkawa S. An in vitro study of highstrength resin posterior denture tooth wear. Int J Prosthodont. 1997;10(1): 28-34.

[PubMed] Google Scholar (34) Scopus (15)

59. Heintze SD, Zellweger G, Grunert l, et al. Laboratory methods for evaluating the wear of denture teeth and their correlation with clinical results. Dent Mater. 2012;28(3): 261-272. D [Full text links] [PubMed] Google Scholar (23) Scopus (14)

60. Heintze SD, Zellweger G, Sbicego S, et al. Wear of two denture teeth materials in vivo-2-year results. Dent Mater. 2013;29(9): e191-e204.

[Full text links] [PubMed] Google Scholar (13) Scopus (10)

61. Mehl A, Gloger W, Kunzelmann KH, Hickel R. A new optica 3-D device for the detection of wear. J Dent Res. 1997;76(11): 1799-807.

[Full text links] [PubMed] Google Scholar (279) Scopus (173)

62. Esquivel-Upshaw J, Hsu S, Abdulhameed $\mathrm{N}$ et al. Volume loss and depth analysis using stylus profiler and laser scanner. Poster No 0668 presented at: IADR/AADR/CADR General Session; March 23, 2017; San Francisco, CA, USA https://iadr.abstractarchives.com/abstract/17iags-2638172/ volume-loss-and-depth-analysis-using-stylus-profiler-andlaserscanner

63. Krejci I, Lutz F, Zedler C. Effect of contact area size on ename and composite wear. J Dent Res. 1992;71(7): 1413-1416. [Full text links] [PubMed] Google Scholar (49) Scopus (30)

64. Condon JR, Ferracane JL. Effect of antagonist diameter on in vitro wear of dental composite. Poster No 954 presented at: AADR/CADR Annual Meeting; March 14, 2003; San Antonio TX, USA.

https://iadr.abstractarchives.com/ abstract/2003SanAnton-27566/effect-of-antagonistdiameter-on-in-vitro-wear-of-dental-composite

65. Schmid-Schwap M, Rousson V, Vornwagner K, Heintze SD. Wear of two artificial tooth materials in vivo: a 12-month pilot study. J Prosthet Dent. 2009;102(2): 104-114.

[Full text links] [PubMed] Google Scholar (26) Scopus (12)

66. Ogle RE, Davis EL. Clinical wear study of three commercially available artificial tooth materials: Thirty-six month results. $J$ Prosthet Dent. 1998;79(2): 145-151.

[Full text links] [PubMed] Google Scholar (64) Scopus (36)

67. Lindquist TJ, Ogle RE, Davis EL. Twelve-month results of a clinical wear study of three artificial tooth materials. J Prosthet Dent. 1995;74(2): 156-161.

[Full text links] [PubMed] Google Scholar (33) Scopus (16)

68. Douglas WH, Delong R, Pintado MR, Latta MA. Wear rates of artificial denture teeth opposed by natural dentition. J Clin Dent. 1993;4(2): 43-47.

[PubMed] Google Scholar (28) Scopus (18) 


\section{Jean-François ROULET \\ DDS, DMD, PhD, Dr hc, Prof hc, Professor, Chair Department of Restorative Dental Sciences, Center for Dental Biomaterials College of Dentistry, University of Florida Gainesville, FL, USA

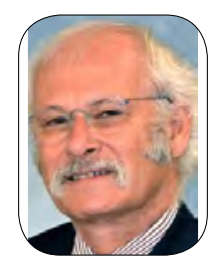

Jean-François Roulet, DDS, Dr med dent, $\mathrm{PhD}$, is the former chair and current professor of the Department of Restorative Dental Sciences at the University of Florida. Professor Roulet is author/coauthor of more than 180 papers, edited/contributed to 27 textbooks and mentored more than 150 theses. He is a renowned international lecturer with over 800 appearances to date. Dr. Roulet is a member of many professional organizations, has won numerous awards, and holds four patents. He is editor of Prophylaxe Impuls and Stomatology Edu Journal. His areas of interest include minimally invasive dentistry, dental materials (ie, composites and ceramics), adhesive dentistry, esthetic dentistry, and application concepts in preventive dentistry.

\section{Ouestions}

\section{Which teeth were worn?}

Da. Ceramic;

b. Double crosslinked PMMA;

ac. PMMA;

口d. Composite.

\section{Which loads were used?}

Da. 50 and $100 \mathrm{~N}$;

b. 20 and $80 \mathrm{~N}$;

ac. 19.6 and $68.6 \mathrm{~N}$;

ad. 20 and $50 \mathrm{~N}$.

\section{How many load cycles were performed?}

Da. 120,000;

ab. 240,000;

ac. 500,000;

ad. 2,222 .

\section{Which result is correct?}

$\square$ a. The high load group showed significantly higher wear:

$\square$ b. The samples showed more wear than the antagonists;

ac. The antagonists showed equal wear in both load groups:

$\square d$. There were no statistically significant differences in wear of the samples.

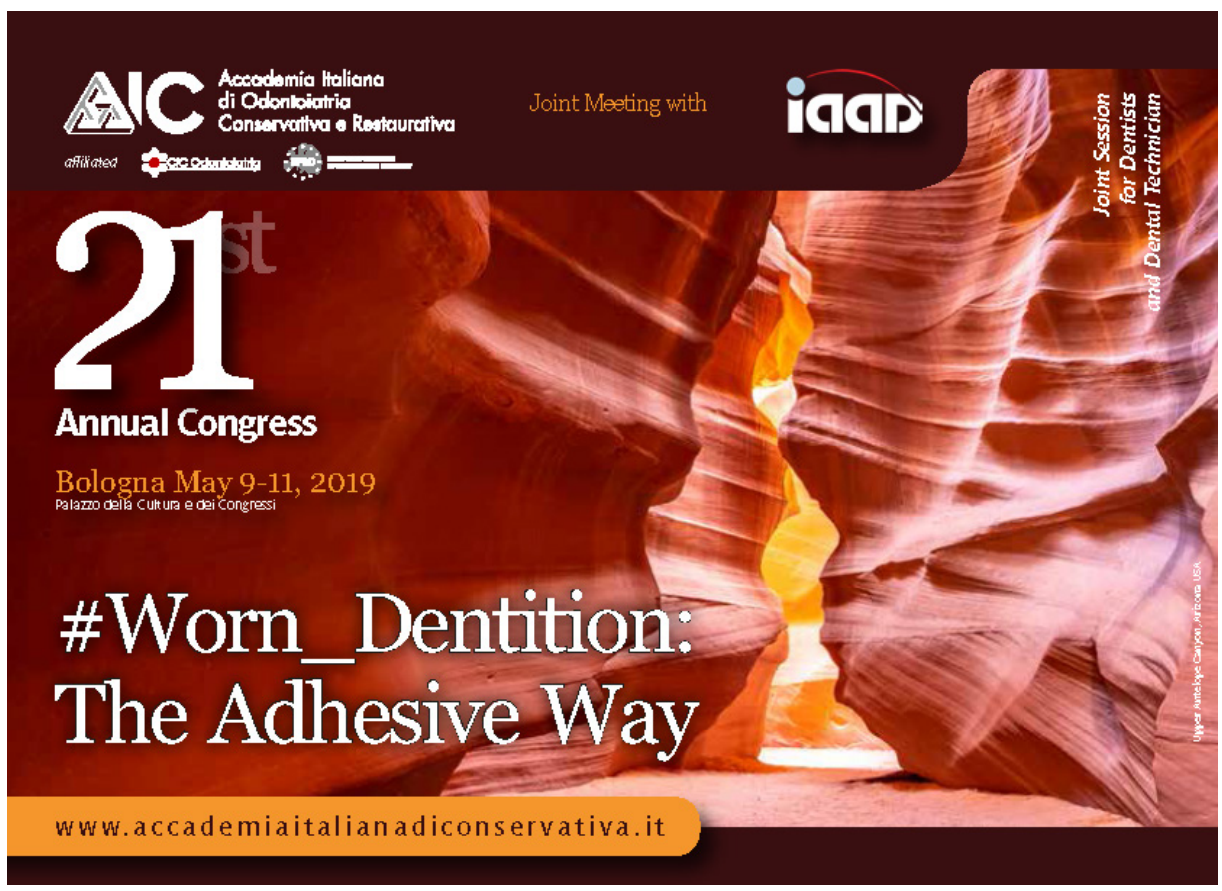

